\title{
The Correlation between High-frequency Vocabulary Size and College English Test-band-four Scores*
}

\author{
Huaqing $\mathrm{He}$ \\ College of Foreign Language Education \\ China West Normal University \\ Nanchong, China
}

\author{
Lijuan Yan \\ School of Foreign Languages \\ China West Normal University \\ Nanchong, China
}

\begin{abstract}
This paper investigates the relationship between the level of high-frequency vocabulary and CET-4 scores of 302 first-year non-English majors of a normal university in China along both the receptive and productive dimensions. The results indicate that (1) students' high-vocabulary size is somewhat restricted and their receptive and productive vocabularies are not balanced, or more precisely, the average receptive vocabulary size is more than twice as great as the average productive vocabulary size; (2) The receptive vocabulary of the students has no significantly positive correlation with their total scores or scores on any part of CET-4, whereas their productive vocabulary has a significantly positive correlation with their total scores and their scores on each part of CET-4; (3) There is a significant difference in high-frequency vocabulary among students of different English language levels. The findings in this paper are a warning for current English vocabulary teaching in China, which focuses on the breadth and reception of vocabulary knowledge while attaching little importance to its depth and production.
\end{abstract}

Keywords-high-frequency vocabulary; receptive vocabulary; productive vocabulary; scores of CET-4

\section{INTRODUCTION}

Language has three components: phonetics, vocabulary and grammar. Phonetics (characters) provides the external form of language and the vocabulary and grammar are its elements and internal structure. In structure, vocabulary is always compared with the bricks of tall buildings and in this way is an extremely important part of a language. Vocabulary ability is a part of communicative competence, and the size of English learners' vocabulary can demonstrate their linguistic proficiency. After several years' research, quite a few researchers have reached the consensus that vocabulary acquisition is the foundation of second language acquisition and vocabulary is the core of language learning [1]. According to the distribution of vocabulary (the coverage), vocabulary can be classified into high-frequency words (everyday vocabulary) and low-frequency words (not everyday vocabulary). Nation [2] believes that vocabulary should be classified into high-frequency vocabulary, academic vocabulary, technical words and low-frequency vocabulary, in which high-frequency words cover most of

*This work was supported by the Meritocracy Research Funds of China West Normal University, under Grant No.17YC067. the vocabulary. In the Brown corpus, the first 2,000 word families cover $79.7 \%$ of written texts, and the first 3,000 cover $84 \%$. These high-frequency words are stems with a strong derivational ability, which can be content words or the bases of compound words with more than one meaning. Therefore, learning high-frequency words is the key to English vocabulary acquisition [3]. This study examines how college students grasp high-frequency words (the first 3,000 word families) and the relation between high-frequency vocabulary and scores on the CET4.

\section{LITERATURE REVIEW}

The size of a speaker's vocabulary is regarded as a significant dimension of his or her vocabulary ability. Schmitt [4] pointed out that vocabulary knowledge is a complex concept whose components are distinct but connected to each other, so that researchers find it hard to test the entirety of a learner's vocabulary. Meanwhile, vocabulary mastery comprises several aspects, of which receptive and productive mastery are the most representative. Therefore, researchers are supposed to test the learner's vocabulary size along both the receptive and productive dimensions. Receptive vocabulary refers to the words of whose meaning one has at least some basic understanding, and productive vocabulary refers to the words which one can actively use in speaking or writing [5]. Some scholars also call receptive vocabulary passive vocabulary, which marks the breadth of the vocabulary knowledge; they call productive vocabulary active vocabulary, which marks the depth of vocabulary knowledge. There is an asymmetry between receptive vocabulary and productive vocabulary: Learners in general have one to five times as much receptive as productive vocabulary [3], which regulates vocabulary acquisition. To both native children and second language learners, receptive vocabulary acquisition precedes productive vocabulary, and there is always a difference between the two [5].

Based on a survey of research papers published in 14 major linguistic journals, both at home and abroad, during a period of ten years (2004-2013), Zhao Wei et al. [6] provide a comprehensive summary and analysis of the research on L2 vocabulary acquisition. Researchers have conducted numerous studies of the relationship between vocabulary knowledge (breadth and depth) and other language skills, 
and these studies show that vocabulary knowledge is positively correlated with other L2 skills. In addition, they pointed out that depth of vocabulary acquisition is the core of vocabulary acquisition research both at home and abroad in comparison with breadth of vocabulary acquisition. Chinese scholars have performed studies on high-frequency vocabulary and found that Chinese students' high-frequency vocabulary level is lower than expected even though they had studied English for six or seven years [7][8][9][10]. Lixia Miao investigated the developmental features of nonEnglish-majors' high-frequency vocabulary acquisition and found that subjects' high-frequency vocabulary develops slowly, both receptively and productively, and that their receptive vocabulary develops much faster than their productive vocabulary [11]. Zhao $\mathrm{Yu}$ has explored the possible connection between EFL adult learners' distribution of noticing and fossilization in the output of high-frequency English words and found a positive correlation between fossilization level and noticing of low-frequency words [12].

Some beneficial conclusions of the theories of vocabulary learning and teaching and interesting revelations have been demonstrated through such research on vocabulary knowledge. However, some deficiencies remain: Firstly, the majority of the studies paid more attention to receptive vocabulary than productive vocabulary. Secondly, much previous research focused on the relationship between vocabulary ability and L2 skills, while only a little research concerned the relationship between vocabulary ability and the learners' English level as a whole. Thirdly, there has not been sufficient research of high-frequency vocabulary. To research these phenomena, this study is intended to explore the relationship between Chinese college students' highfrequency vocabulary levels and their CET-4 scores along both the receptive and productive dimensions.

\section{RESEARCH DESIGN}

This research empirically examined the relationship between Chinese college students' high-frequency vocabulary size and their English levels in the receptive and productive dimensions in order to serve as a reference for reform of vocabulary teaching.

\section{A. Research Questions}

This research sought to answer the following three questions:

- What is the nature of non-English majors' basic knowledge of high-frequency vocabulary? To be more precise, how large are their receptive and productive vocabularies?

- What is the relation between their receptive and productive vocabularies and their scores on CET4 as a whole and on each part?

- What is the difference in high-frequency vocabulary among students of different English language levels?

\section{B. Participants}

This study involved 302 participants, all of them nonEnglish majors. All participants were first-year students from six classes at a normal university in Sichuan China. Among the 302 participants, 250 were female, 52 male. They majored in three different areas: Chinese (112), Mathematics (120) and Business administration (70). Their average English score on the Gaokao (College Entrance Examination Test) was 106 (a possible 150 total) and on the CET4 was 406 (a possible 710 total, with 425 as the passing score).

\section{Instruments}

Three tests were used to collect data.

1) The productive levels test: Version $\mathrm{C}$ made by Laufer and Nation [13] is to test students' productive vocabulary size. The test's content has been verified several times, so it has high reliability [13][14][15]. This test was constructed from the Academic Word List (AWL) at the following four frequency levels: the 2,000 level, 3,000 level, 5,000 level, and 10,000 level, with the 2,000 level containing the most frequent words. It is important to note that the AWL is not based on general frequencies. Rather, it consists of 570 word families beyond the 2,000 level which are frequent in academic texts. In this test, short sentences composed with the 2,000 high-frequency words are used to lead learners to come up with the target words. To avoid more than one correct answer on a question, the first one or several letters are given. For example: This sweater is too tight. It needs to be stret__. In this test, there are 18 questions at the very high vocabulary frequency level. As this study only concerns the high-frequency 3,000-word families in total (word families are used as the units of vocabulary), only the first two vocabulary frequency layers were chosen, the 2,000- and 3,000-word families, for 36 questions total. Both the spelling and grammar are corrected and marks given. In this way, the participants can be tested on more aspects of productive vocabulary, such as the form of words and grammar [2] [9] [16] [17].

2) A vocabulary level test: Test $\mathrm{B}$, which was initially made by Nation and then adapted by Schmitt et al. [18]. The internal reliability of the test contents has been verified several times and can exceed 0.8 , which is a high reliability $[14][15][18][19]$. This test is used to test the learners' target-language vocabulary ability without context. As the productive vocabulary tests, it is composed of five layers with the vocabulary in the same column. In the test, there are ten blocks in each column, and each block includes three questions, for a total of 30 questions. As with the productive vocabulary test, only the first two layers of the vocabulary frequency were chosen. Therefore, there are 60 questions in total. Each block includes six English words and participants were required to choose three of them to match the English meanings. For example:

\section{1. business}

2. clock _ _ _ _ part of a house 
3. horse 3 animal with four legs

4. pencil 4 __ something used for writing

\section{5. shoe}

6. wall

3) CET4: CET4 is designed to test the effect of the classes for Levels 1 to 4 on college students. The CET4 has social importance, and its reliability and validity are very high after being applied for more than 20 years. In the school in this study, students who are not English majors can be allowed to take the CET4 at the end of Year 1.

4) Procedure: To make sure of the data's reliability and validity, the two vocabulary tests were used in class at the beginning of June 2016, a week before CET4 was administered. As the receptive and productive vocabulary tests were drawn from the same vocabulary, some words on the two tests overlap. To be precise, some words in the receptive vocabulary test are target words in the productive test, which might provide cues for the test. Therefore, when testing, the productive vocabulary should be tested first and the participants should then be given the receptive vocabulary test after the first test has been handed in to the teacher. The test will last about 15 to 30 minutes. During this time, the participants have to finish on their own and are not allowed to refer to a dictionary. Meanwhile, they are required to write down relevant personal information: their student number and name. Because the answers of the two tests are unambiguous, the reliability is high. The scores on each layer in the tests are converted into the vocabulary size, which allows the total vocabulary size to be estimated. Later, the grades on the CET4 were collected at the end of August.
SPSS21.0 was then used to analyse the collected data. Firstly, descriptive statistics were used to analyse the highfrequency vocabulary. Secondly, analysis was performed to yield the partial correlations (net correlations) among the high-frequency vocabulary sizes, the total scores on the CET4, and the scores on each part. Consequently, the size of productive vocabulary and receptive vocabulary were the controlled variables; the 'zero order correlation coefficient' was calculated and then the zero order correlation coefficient and net correlation coefficients between different variables were obtained. Lastly, an independent-samples t-test was conducted to test the differences of the two samples' highfrequency vocabulary sizes.

\section{RESEARCH RESULTS AND DISCUSSION}

\section{A. The Basic Knowledge of High-frequency}

"Table I" shows that subjects' mean receptive vocabulary size was 1,605 word families, with a standard deviation of 277 ; the minimum vocabulary size was 533 , while the maximum was 2,000. In the 2,000-3,000 layer, there were $607,137,200$, and 900 word families, respectively; in the 3,000 layer, the high-frequency vocabulary included, respectively, 2,212, 387, 733 and 2,833 word families. Meanwhile, in the 2,000 layer, college students' average productive vocabulary size was 756 word families, with a standard deviation of 324 ; the minimum size of vocabulary was 1 and the maximum was 1,667. In the 2,000-3,000 layer, there were 149, 92, 1 and 389 word families, respectively, and in the 3,000 layer, the sizes of the high-frequency vocabulary were 905, 380, 2 and 1,833 word families, respectively.

TABLE I. Descriptive Statistics For College StUdENTS' High-FrequenCy Vocabulary Size $(\mathrm{N}=302)$

\begin{tabular}{cllllll}
\hline & $\begin{array}{c}\text { Receptive } \\
\mathbf{2 , 0 0 0}\end{array}$ & $\begin{array}{c}\text { Receptive } \\
\mathbf{2 , 0 0 0 - 3 , 0 0 0}\end{array}$ & $\begin{array}{c}\text { Total receptive } \\
\text { vocabulary } \mathbf{( 3 , 0 0 0 )}\end{array}$ & $\begin{array}{c}\text { Productive } \\
\mathbf{2 , 0 0 0}\end{array}$ & $\begin{array}{c}\text { Productive } \\
\mathbf{2 , 0 0 0}-\mathbf{3 , 0 0 0}\end{array}$ & $\begin{array}{c}\text { Total productive } \\
\text { vocabulary }(\mathbf{3 , 0 0 0})\end{array}$ \\
\hline Mean Value & 1,605 & 607 & 2,212 & 756 & 149 & 905 \\
Standard deviation & 277 & 137 & 387 & 324 & 92 & 380 \\
Minimum value & 533 & 200 & 733 & 1 & 1 & 2 \\
Maximum value & 2,000 & 900 & 2,833 & 1667 & 389 & 1,833 \\
\hline
\end{tabular}

The mean numbers of receptive words of the participants in this study are a little lower than in the study of Cui and Wang [20]. The participants play a vital role. The participants of Cui and Wang's study [20] were English majors, while this study included non-English majors. Moreover, the college students' receptive and productive vocabularies were found to be asymmetrical in this study, so that the mean size of the productive vocabulary is only $41 \%$ that of the receptive vocabulary, compared to $49 \%$ and $52 \%$ in the studies by Zhang [14] and Wang [21], respectively. Similarly, the educational background of the participants influenced the results, because the participants in their studies were from leading universities, while this study's participants were from an ordinary normal university.

We must point out that compared with the results of He's study [9], at the 2000 level the freshmen's receptive vocabularies are larger than those of students in the third

year of high school but their productive vocabularies are smaller, which might be due to intensive study in the third year. Thus, the students who will pass the College Entrance Examination will have practiced a lot and will be more familiar with using and spelling the words. All in all, the participants' mean sizes of receptive and productive vocabularies are not large. Under the condition of 3,000 word families total, there were still more than 700 words whose meanings were not understood, and $2 / 3$ of the vocabulary was incorrectly produced. There were many mistakes in spelling, the singular and plural forms of nouns, and the tenses of verbs. Therefore, students' high-frequency vocabulary size needs to be enlarged.

\section{B. Relation between the High-frequency Vocabulary Size and the Scores on CET4}

Pearson's correlation coefficients of the data from the study along the receptive and productive dimensions were 
used to analyse the relation between the high-frequency scores and the scores on the CET4.

1) Analysis of zero order correlation among productive and receptive vocabulary size and the total and part scores on the CET4: Originally, there was no variable for the relationships between each sample. The zero order correlation oblong as in "Table II" shows that receptive vocabulary size has different levels of positive correlation with the total CET4 scores and the scores on listening, reading and writing (including writing and translation), which is almost the same as Wang's [22] results. Productive vocabulary size also has different levels of positive correlation among the CET4 scores and the scores on listening, reading and writing (including writing and translation), with correlation coefficients of .597, .439, .490 and .441, reaching statistical significance at the 0.01 apparent level, which is also almost the same as Wang's [22] results. The statistics show that at the same time the total and part scores on CET 4 and the sizes of receptive and productive vocabularies have different levels of correlation.

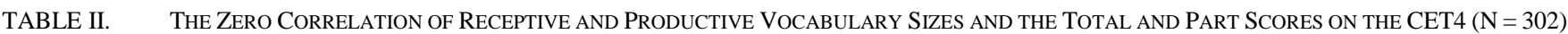

\begin{tabular}{|c|c|c|c|c|c|c|}
\hline & CET4 scores & Listening & Reading & Writing & $\begin{array}{c}\text { Receptive } \\
\text { vocabulary size }\end{array}$ & $\begin{array}{c}\text { Productive } \\
\text { vocabulary size }\end{array}$ \\
\hline CET4 scores & 1.000 & $.729 * *$ & $.850 * *$ & $.711^{* *}$ & $.361 * *$ & $.597 * *$ \\
\hline Listening & $.729 * *$ & 1.000 & $.380 * *$ & $.377 * *$ & $.264 * *$ & $.439 * *$ \\
\hline Reading & $.850 * *$ & $.380 * *$ & 1.000 & $.415^{* * *}$ & $.293 * *$ & $.490 * *$ \\
\hline Writing & $.711 * *$ & $.377 * *$ & $.415 * *$ & 1.000 & $.271 * *$ & $.441 * *$ \\
\hline Receptive vocabulary size & $.361 * *$ & $.264 * *$ & $.293 * *$ & $.271 * *$ & $1.000 * *$ & $.382 * *$ \\
\hline Productive vocabulary size & $.597 * *$ & $.439 * *$ & $.490 * *$ & $.441 * *$ & $.382 * *$ & 1.000 \\
\hline
\end{tabular}

In statistics, a mean absolute value of a correlation coefficient falling between 0.20 and 0.40 indicates a weak correlation; between 0.40 and 0.70 an effective correlation or moderate correlation; and between 0.70 and 0.90 a strong correlation [23]. According to the standards in statistics, the receptive vocabulary size has a weak correlation with the total and part scores on CET4; the productive vocabulary size has a moderate correlation with the total and part scores on CET4. The CET4 scores have a strong correlation with listening, reading and writing scores; productive vocabulary size has a weak correlation with receptive vocabulary size.

2) Partial correlation analysis of the size of receptive vocabulary and the total and part scores on CET4: For this part of the study, we controlled the variable 'productive vocabulary size' to analyse the partial correlations among receptive vocabulary size and the total and part scores on the CET4. "Table III" shows that the partial coefficient of receptive vocabulary size and the total CET4 scores and scores on listening, reading, writing and other parts are $.180, .116, .131$ and .124 , with apparent correlations of .021, .137, .093 and .113. That means that receptive vocabulary size has no significant correlation with listening, reading or writing $(\mathrm{p}>0.05$, does not reach the significance level), and only receptive vocabulary size has a weak correlation with CET4 scores $(\mathrm{r}=.180, \mathrm{p}=.021)$. In statistics, correlations with mean absolute values lower than 0.20 indicate a very weak relationship and can be omitted [23].

TABLE III. THE PARTIAL CORRELATIONS AMONG RECEPTIVE VOCABULARY SizE AND TOTAL AND PART CET4 SCORES $(\mathrm{N}=302)$

\begin{tabular}{lllll}
\hline & CET4 scores & Listening & Reading & Writing \\
\hline Relative & .180 & .116 & .131 & .124 \\
$\begin{array}{l}\text { coefficient } \\
\text { Significance }\end{array}$ & .021 & .137 & .093 & .113 \\
(two sided) & & & & \\
\hline
\end{tabular}

3) Partial correlation analysis of the productive vocabulary size and total and part CET4 scores: For this part of the study, we control the variable 'productive vocabulary size' and analyse the partial correlations among productive vocabulary size and total and part CET4 scores. "Table IV" shows that the partial coefficients for productive vocabulary size and total CET4 scores and those for listening, reading, writing and other parts are $.532, .380, .428$ and .380 , and its apparent relation is $.000(\mathrm{p}<.001)$, that is, productive vocabulary size has a weak correlation with listening and writing level and there is a moderate correlation between reading and CET4 scores, which means that the larger the productive vocabulary size, the higher the students' scores.

TABLE IV. THE PARTIAL CORRELATIONS AMONG PRODUCTIVE VOCABULARY SIZE AND TOTAL AND PART CET4 SCORES $(N=302)$

\begin{tabular}{lllll}
\hline & CET4 scores & Listening & Reading & Writing \\
\hline $\begin{array}{l}\text { Relative } \\
\text { coefficient }\end{array}$ & $.532^{* * *}$ & $.380^{* *}$ & $.428 * *$ & $.380^{* *}$ \\
$\begin{array}{l}\text { Significance } \\
\text { (two-sided) }\end{array}$ & .000 & .000 & .000 & .000 \\
\hline & & b. $_{* *}$ Correlation is significant at the 0.01 level (2-tailed).
\end{tabular}

Comparing "Table III" and "Table IV", we can see, when controlling for the 'productive vocabulary size' variable, receptive vocabulary size has no relation with the scores on each part and a statistically insignificant relation with CET4 scores. This means that receptive vocabulary size has no predictive value for the proficiency of college students. When controlling for the 'receptive vocabulary size' variable, productive vocabulary size has a significant correlation with the scores on each part of CET4, which means productive vocabulary size can predict students' college English level and proficiency on each skill. Therefore, the key to improving students' English levels is enlarging their productive vocabulary. 
"Table V" further shows the correlation coefficients of each level of productive vocabulary with the total and part CET4 scores. From this table, correlation coefficients of the 2,000 level scores with the scores on CET4 and listening, reading and writing are $.568, .404, .483$ and 407 , and for the 3,000 level they are.464, .389, .324, and .387 , for which the significances are $.000(\mathrm{p}<.01)$. This means that the participants' vocabulary sizes in the 2,000 and 2,000-3,000 levels are significant relative to the CET4 scores and the scores on each part. However, the correlations at the 2,000 level are larger than at the 2,000-3,000 level, which means the participants' productive vocabulary size on the 2,000 level has a closer relation with the total and part scores on CET4.

TABLE V. THE CORRELATION AMONG VocABUlary LEVELS AND TOTAL AND PART CET4 SCORES

\begin{tabular}{|c|c|c|c|c|c|}
\hline & & $\begin{array}{r}\text { CET4 } \\
\text { scores } \\
\end{array}$ & Listening & Reading & Writing \\
\hline \multirow[b]{2}{*}{2000} & Correlation & $.568 * *$ & $.404 * *$ & $.483 * *$ & $.407 * *$ \\
\hline & $\begin{array}{l}\text { Significance } \\
\text { (two- sided) }\end{array}$ & .000 & .000 & .000 & .000 \\
\hline & Correlation & $.464 * *$ & $.389 * *$ & $.324 * *$ & $.387 * *$ \\
\hline 2000-3000 & $\begin{array}{l}\text { Significance } \\
\text { (two- sided) }\end{array}$ & .000 & .000 & .000 & .000 \\
\hline
\end{tabular}

\section{Comparison of the High-frequency Vocabulary Size of Students in Different English Levels}

To further explore the relation between high-frequency vocabulary size and CET scores, the 100 highest- and lowest-scoring participants were divided into two groups according to their CET4 scores, the high-score group (50) and the low-score group (50), and the differences between the two were analyzed with an independent-sample t-test. According to the statistics in "Table VI", the low-score and high-score groups contain 2,061 and 2,321 word families respectively, which difference is very significant $(\mathrm{t}=-3.468$, $\mathrm{p}=.001)$. The mean productive vocabulary sizes of the lowscore and high-score groups are 612 and 1,129 word families, respectively. That is, the high-score group's productive vocabulary size is twice as large as the low-scores group's, which difference is significant $(\mathrm{t}=-8.311, \mathrm{p}=.000)$. Meanwhile, the standard deviation for the low-score group is larger than that for the high-score group, meaning the differences between receptive and productive vocabulary sizes are much larger in the low-score group. Therefore, for the low-score group to improve their English and catch up with the high-score group, they must focus on highfrequency vocabulary and enlarge their receptive and productive vocabularies. However, the productive vocabulary is the key, as it strengthens learners' ability to produce vocabulary correctly. Moreover, the search, extraction and output of vocabulary knowledge are based on a higher-level output procedure and ability, which requires students to put more energy into the spelling, meaning and function of the words.

TABLE VI. DESCRIPTIVE STATISTICS OF THE High-FREQUENCY VOCABUlARY SiZE FOR THE HiGH-SCORE AND LOW-SCORE GROUPS

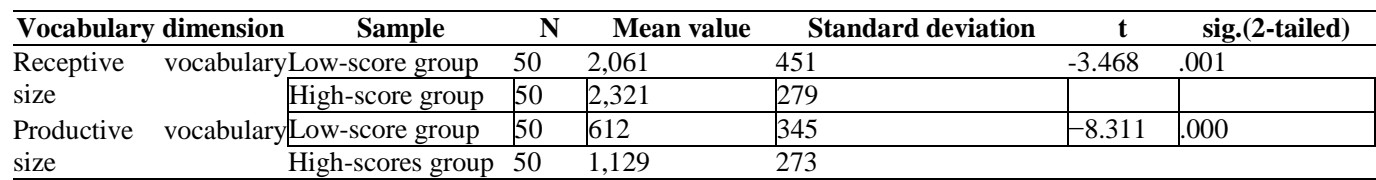

\section{CONCLUSION}

High-frequency vocabulary has high coverage and usage, which is the most important part of vocabulary learning. This research shows that learners' vocabulary size needs to be improved in both the receptive and productive dimensions; in particular, the productive vocabulary is too small and must be improved. Compared with receptive vocabulary, the size of the productive vocabulary has a closer relation with the student's English level and listening, reading, writing and other skills, so it can indicate the English level more closely. The results of this study show that the rate of correct output in participants' high-frequency vocabulary is low, which influences the development and improvement of the English level as a whole as well as each skill. To solve this problem, textbooks, teachers and students are supposed to be integrated and used synthetically. Firstly, the input of vocabulary knowledge is the basis of output. Textbooks are the main material of students' input. Therefore, the repeat rate of vocabulary should be improved when adapting the textbooks. Secondly, teachers should give importance to teaching high-frequency vocabulary, explaining it clearly, and encouraging students to use the vocabulary that has been learned more often in speaking and writing. Thirdly, students need to use different ways of learning vocabulary actively and converting receptive vocabulary into productive vocabulary rapidly to improve the level of language use and the depth of high-frequency vocabulary. We note that this research is based on an empirical study, which also has certain limitations, such as the participants being from an ordinary normal university and the ways the vocabulary was tested were relatively simple. These should be improved in later studies.

\section{REFERENCES}

[1] Z. Chen and L. Wang, "On strategies of word acquisition of bilinguals: A case study," Shandong Foreign Language Teaching Journal, vol. 4, pp. 68-73, 2006.

[2] I. S. P. Nation, 2001. Learning Vocabulary in Another Language. Cambridge: Cambridge University Press. pp. 416-428, 2001.

[3] S. Gui, "Aspects of English vocabulary learning," Foreign Language World, vol. 1, pp. 57-65, 2006.

[4] N. Schmitt, Researching Vocabulary. Beijing: Foreign Language Teaching and Research Press, 2015. 
[5] B. Laufer, "The development of passive and active vocabulary in second language: Same or different?," Applied Linguistics, vol. 19, pp. 255-271, 1998.

[6] W. Zhao, Y. Chen, and W. Lu, "An analysis of the research on L2 Vocabulary Acquisition: Based on papers published in 14 major linguistic journals both at home and abroad in the past 10 years (2004-2013)," Foreign Language World, vol. 4, pp. 39-46, 2014.

[7] Z. Hong, "A study of senior high school students' English vocabulary proficiency," English Teaching and Research of Middle and Primary Schools, vol. 11, pp. 53-56, 2005.

[8] G. Ma, "A study of secondary-level students' English high-frequency vocabulary proficiency," Foreign Languages and Their Teaching, vol. 1, pp. 19-21, 2006.

[9] H. He, "An empirical study on senior high school students' English high-frequency vocabulary proficiency," Foreign Language Education in China, vol. 4, pp. 53-59, 2016.

[10] H. He and W. Chen, "An empirical study on college students' English high-frequency vocabulary proficiency," Journal of China West Normal University, vol. 2, pp. 43-47, 2008.

[11] L. Miao, "Developmental pattern of non-English majors' highfrequency vocabulary acquisition at their fundamental stage," Journal of Beijing International Studies University, vol. 10, pp. 73-78, 2010.

[12] Y. Zhao, "Fossilization in the output of high-frequency words from the 'noticing' perspective," Foreign Language Research, vol. 3, pp. 100-102, 2011.

[13] B. Laufer and P. Nation, "A vocabulary size test of controlled productive ability," Language Testing, vol. 16, pp. 36-55, 1999.

[14] X. Zhang, "The relationship between lexical knowledge and listening comprehension of TEM 4," Foreign Language World, vol. 2, pp. 3642, 2011.

[15] X. Zhang, "The influence of vocabulary size and productive lexical knowledge on L2 oral production," Foreign Language World, vol. 4, pp. 34-41, 2015.

[16] K. I. Abdullah et al., "Validation of a controlled productive vocabulary levels test below the 2000-word level," System, vol. 41, pp 352-364, 2013.

[17] L. Bai and C. Dai, "The impacts of different frequency bands and dimensions of lexical knowledge on the ability of reading and writing," Foreign Language Learning Theory and Practice, vol. 2, pp. 72-78, 2013.

[18] N. Schmitt, D. Schmitt, and C. Clapham, "Developing and exploring the behavior of two new versions of the vocabulary levels test." Language Testing, vol. 18, pp. 55-88, 2001.

[19] Y. Wang, "The study on the relationship between vocabulary knowledge and L2 lexical inferencing performance," Foreign Language World, vol. 6, pp. 32-38, 2013.

[20] Y. Cui and T. Wang, "Developments and relationships of receptive vocabulary size, productive vocabulary size and depth of vocabulary knowledge," Modern Foreign Languages, vol. 4, pp. 392-400, .2006.

[21] T. Wang, M. Wu and X. Hou, "Relationship between the breadth and depth of vocabulary and grammatical knowledge and listening comprehension." Technology Enhanced Foreign Language Education, vol. 6, pp. 42-46, 2011.

[22] Z. Wang, "An empirical study of the predictability of the Vocabulary Size Test on language proficiency," Foreign Language Learning Theory and Practice, vol. 2, pp. 71-75, 2014.

[23] X. Qin, Quantitative Data Analysis in Foreign Language Teaching and Research, Wuhan: Huazhong University of Science and Technology, 2003. 